\title{
IDÉIAS
}

\section{E preciso repensar o Estado e suas relações com a sociedade}

\author{
Maria do Socorro M. V. de Carvalho (")
}

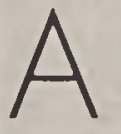

Reforma Administrativa recoloca mais uma vez em discussão o problema da inovação e mudança na administração pública, que tanto tem preocupado aqueles que, de uma forma ou de outra, ocupam-se das questðes pertinentes ao desempenho do aparato governamental.

A idéia de Reforma Administrativa tem aparecido como estratégia através da qual se busca inovar na administração pública, objetivando torná-la um instrumento ágil para a implementação das políticas de Governo.

Discutir Reforma Administrativa significa discutir o próprio papel do Estado e do aparato de que se utiliza para garantir a prestação dos servicos demandados pela sociedade. Como a administração pública assume tracos do Estado que integra, temos primeiro que repensar o Estado Brasileiro e suas relaçōes com a Sociedade.

Assim não é de estranhar que sempre que ocorrem mudanças no Sistema Politico da Pais, surjam movimentos de Reforma Administrativa, exatamente para adequar a máquina do Governo às diretrizes de sua Politica. É preciso notar que a primeira grande Reforma da Administração Pública Federal, ocorrida nas décadas de $30 / 40$, surgiu sob a égide do Estado Novo. A última reforma, consubstanciada no Decreto-lei 200/67, foi conduzida sob orientação do primeiro Governo Revolucionário de 1964.

Hoje, estamos vivendo uma nova fase no pais, em que a sociedade de-

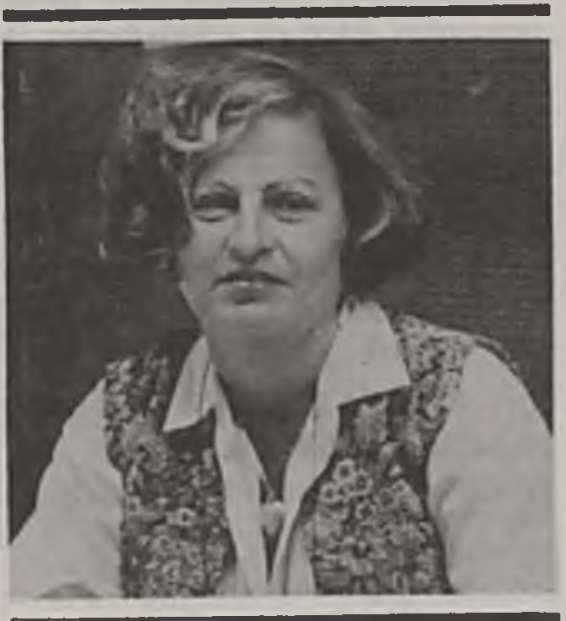

manda uma maior participação democrática. A Nova República retoma o ideal reformista, anunciando a realização de um amplo debate, com a participação de todos os segmentos da Sociedade.

E natural que, na Nova República, o Governo considere prioritário a Reforma da Administração Pública, para eliminar da máquina do Estado caracteristicas consideradas em desacordo com os ideais -que fundam a Aliança Democrática.

De acordo com os pronunciamentos do Sr. Ministro da Administração, Aluizio Alves, faz-se necessário remover as camadas de inércia e remover as caministração pública e dotá-la de simplicidade e clareza, ou seja de transparência democrática. $\dot{E}$ necessário instituir uma base orgânica, moderna, ágil e competitiva para que o formidável aparato do Estado se torne realmente instrumento a serviço do bem comum.

Administraço Pública pela Escola Brasileira de Administraça Pública da Fundaço Getúllo Vargas e professora do Departamento de Administraçáo da Universidade de Brasilia, UnB
O objetivo maior das experiências de reforma adminstrativa, conforme se pode observar a partir de uma análise retrospectiva, tem sido sempre o de oferecer maior eficiência à máquina do Estado, para tornar possivel a implementação dos planos e programas de Governo. O que tem variado, ao longo de meio século, têm sido as prioridades estabelecidas e as premissas que servem de fundamento à Reforma. Mesmo em relação a prioridades e premissas, ê possivel identificar, tomando por base o excelente trabalho de pesquisa de Beatriz Wahrlich, idéias muito semelhantes. Veja-se, por exemplo, que a Reforma Administrativa desenvolvida nas décadas de $30 / 40$, considerou como uma das áreas principais de reforma a Administração de Pessoal, tendo o sistema do mérito como pedra angular.

A Reforma de 1967 , bem como a que ora se inicia no Pais, também considera o fortalecimento do sistema do mérito um dos seus principais objetivos. Afirma o Ministro Aluizio Alves que para reformar a base do serviço público, é necessário elevar a condição do mérito como primordial e prioritária.

Outra premissa básica da Reforma que ora se propóe - voltar o esforço da reforma da administração pública federal para a valorização do usuário do serviço público - também esteve presente nas reformas de $1930 / 40$ e 1967.

Joaquim Neves afirma que, na reforma das décadas de $(1930 / 40)$, chegou-se ao requinte de criar a denominação servidor público para dar a dimensão do seu verdadeiro papel. Também se procurou enfatizar os valores morais que deveriam orientar o comportamento do servi- 


\section{IDÉIAS}

dor público. Chegou-se mesmo a criar um slogan de que o verdadeiro servidor público era aquele que tinha como norma de vida: pobreza e anonimato.

O Ministro Hélio Beltrão, inspirador e líder do Programa Nacional de Desburocratização, instituido em 1979, afirma que o Programa foi criado para dar inicio a uma transformação essencial no comportamento da Administração Pública em relação a seus usuários: investir o usuário na condição de cidadão destinatário de toda a ação do Estado, ou seja fazer com que os usuários passem da condição de súditos à de cidadãos.

Uma das premissas básicas da atual reforma consiste em limitar a abrangência extensiva da ação estatal. Pretende-se racionalizar a máquina do Estado que se hipertrofiou, amortecendo a iniciativa privada e the tirando espaço. Tal hipertrofia seria responsável pela perda da eficácia da administração pública e pelo distanciamento de seus propósitos de bem servir ao cidadão e de executar eficientemente os Planos do Governo.

Observe-se que o diagnóstico do gigantismo da administração pública já foi considerado na proposta de reforma consubstanciada no Decreto-lei $200 / 67$, que preconiza a transferência para a iniciativa privada da prestação de serviços que, por sua natureza, podem ser melhor executados fora do âmbito da Administração Pública.

Mais recentemente o Programa Nacional de Desestatizaçao foi instituído para fortalecer o sistema de livre empresa, objetivando transferir para a iniciativa privada empresas que estavam na órbita do Estado e cujas finalidades poderiam ser methor atingidas fora dele.

Como se pode observar, a partir dos exemplos aqui colocados, os diversos movimentos de Reforma por que tem passado a administração pública brasileira têm procurado assegurar à máquina governamental maior eficiência e eficácia, e ao mesmo tempo circuscreve a sua ação aos limites impostos pela norma constitucional. Tais esforços não parecem ter logrado o êxito esperado.

Uma análise conjuntural nos fornece um quadro bastante caótico. Além do gigantismo, podemos ob- servar como caracteristicas mais evıdentes da administração pública brasileira a superposição de atividades, o paralelismo de ações, a desarticulação, a excessiva centralização, que resultam em baixa eficiência, pouca eficácia e discutivel efetividade*.

Somos forçados a questionar até que ponto a reforma administrativa é uma estratégia eficaz para introduzir a inovação e alcançar efetivas mudanças na administração pública brasileira.

Quanto aos agentes da Administração - os servidores públicos apresentam-se extremamente desestimulados, face ao achatamento salarial a que têm sido submetidos, à falta de perspectiva de carreira e à

\begin{tabular}{|c|}
\hline O objetivo maior da \\
reforma administrativa \\
é tornar o Estado \\
mais ágil e oferecer \\
condiços para que \\
se efetivem as metas \\
definidas pelo Governo, \\
no seu esforço para \\
valorizar o social e \\
realizar as mudanças \\
prometidas pela \\
Nova República, ao \\
longo das campanhas \\
que a antecederam. \\
\hline
\end{tabular}

ausência de benefícios complementares. Acrescenta-se a isto a multiplicidade de formas de ingresso ao serviço público, responsável por um quadro heterogêneo composto de servidores nem sempre capazes de executar com eficiência e competência suas funçőes.

Como reverter este quadro, se as diferentes tentativas de Reforma Administrativa não têm apresentado um resultado significativo? É urgente questionar o que se pode esperar da Reforma em curso, antes que o processo se consuma sem alcançar seus objetivos. $\dot{E}$ imperioso refletir

- Para melhor compreensáo da utilizaçáo desses conceitos no contexto da admi-. nistraçáo pública brasileira, ver MOTTA, Paulo Roberto - "Doutrinas de Inovaçăo na Administraçăo Pública: A questão de valores". RAP/FGV: sobre os sucessos e insucessos das experiências anteriores de Reforma, identificando as razoes que contribuíram para tais resultados. Somente a partir dai é possível definir estratégias alternativas, que possam ser utilizadas para modernizar a administração pública. Um dos possiveis campos de investigação é procurar identificar os mecanismos que precisam ser acionados para o engajamento do servidor público no esforço permanente de modernização da ação da burocracia governamental.

Penso que a reforma como estratégia de mudança está em crise de eficácia. A questão maior que se coloca neste momento é a mobilização da sociedade, como um todo, em prol do melhor desempenho da administração pública. E preciso devolver ao cidadăo a crença na capacidade da administração pública de gerenciar adequadamente os recursos que a sociedade coloca à sua disposição. A maximização do bemestar social, a universalizaça do atendimento e a equanimidade na prestação são propósitos permanentes de qualquer processo de reforma de Administração Pública.

Como profissional da Administração de Recursos Humanos, tenho a convicção de que as Reformas não se efetivam sem o concurso das pessoas. Sabe-se, entretanto, que nem sempre a Administração Pública Brasileira tomou medidas efetivas para preencher seus quadros com pessoas identificadas com os valores mais positivos do serviço público. Conseqüentemente, não estão aptas a assumir conscientemente seu papel de servidor público, fiéis aos interesses maiores da sociedade e não orientadas para a satisfação de interesses próprios ou particularizados, como temos observado à saciedade.

Por outro lado, é importante assinalar-que nos acostumamos com uma certa impunidade no Brasil. Os agentes públicos não são cobrados pela sociedade em relação aos seus atos. O formalismo presente na $\mathrm{Ad}$ ministração Pública, fundado na doutrina da neutralidade burocrática, estimula o controle sobre o cumprimento de normas, regras e tradiç̋es, desprezando o resgate de compromissos com resultados socialmente relevantes. É possivel esperar 


\section{IDÉIAS}

que a Reforma venha contribuir para a superação desses vicios?

Acredito que só se obtém algum sucesso na modernização da administração pública, quando se atua na cabeça das pessoas. Mudanças culturais só se consumam em mais de uma geração. Não será mais fácil mudar estruturas do que o comportamento das pessoas? Espero que a Reforma Administrativa que ora se inicia procure mobilizar, através da educaçāo, da participaçāo e do treinamento, todos os servidores, notadamente os de nivel gerencial, para o esforço de construção de uma nova administração pública. Mas que seja capaz também de mobilizar a sociedade brasileira no sentido de maior participação e controle das aç̋es dos administradores. É preciso haver congruência entre o discurso e as práticas vigentes. $\mathrm{O}$ discurso oficial da nova república estabelece o mérito e a competência do servidor como valores fundamentais que precisam ser fortalecidos. E na prática, o que estamos fazendo para converter a retórica em açå?

\begin{tabular}{|c|}
\hline Ao longo deste meio \\
século, têm variado \\
as prioridades e as \\
premissas que servem \\
de fundamento a \\
Reforma. Mesmo assim, \\
ocorrem idéias muito \\
semelhantes e até o \\
sistema do mérito foi \\
a pedra angular da \\
reestruturação que o \\
Estado Novo tentou \\
dos anos trinta até \\
meados dos quarenta.
\end{tabular}

Espero que o Governo venha efetivamente a desempenhar esforços sistemáticos e permanentes para a formaça de quadros mais comprometidos com os valores de austeridade, probidade e uso adequado dos recursos públicos, essenciais a uma administração pública que se quer democrática.

\section{Fórum debate ética para o Serviço Público}

\section{Dielai Carvalho Pereira (*)}

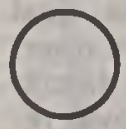

Fórum de Debates sobre as Diretrizes da Refoma da Administração Pública Federal, promovido nos dias 13 e 14 de marco, pelo $\mathrm{Mi}$ nistério da Administração, foi um marco importante no processo brasileiro de reorganização institucional, que certamente antecipa o grande debate nacional em torno da Constituição.

A tônica predominante nas reflexỏes foi o novo comportamento do cidadão brasileiro, despertado com o programa de estabilidade econômica do Presidente Sarney. Sob diferentes ângulos e fundamentaçðes ou conceitos, as importantes contribuiçðes trazidas ao debate nacional por Carlos Lessa, Clóvis Ferro Costa, Deputado Irajá Rodrigues, Deputado José Gregori, Ministro Bento Bugarin, Jorge Hori, Piquet Carneiro, Ministro Xavier de Albuquerque, Senador Severo Gomes e pelos demais debaledores somaram-se às propostas da Câmara I, da Comissão Geral da Reforma da Administração Pública Federal, constituida pelo Ministro Aluizio Alves, em outubro de 1985.

Alcançou-se, nessa primeira etapa, o objetivo do Fórum, com ampla discussão das idéias formuladas no âmbito da Câmara I, encarregada de sugerir a estratégia governamental de mudança, visando a dotar o serviço público de condições institucionais, administrativas e gerenciais mais adequadas ao processode democra tização que o Pais vem atravessando.

Os temas de debate - Funções do

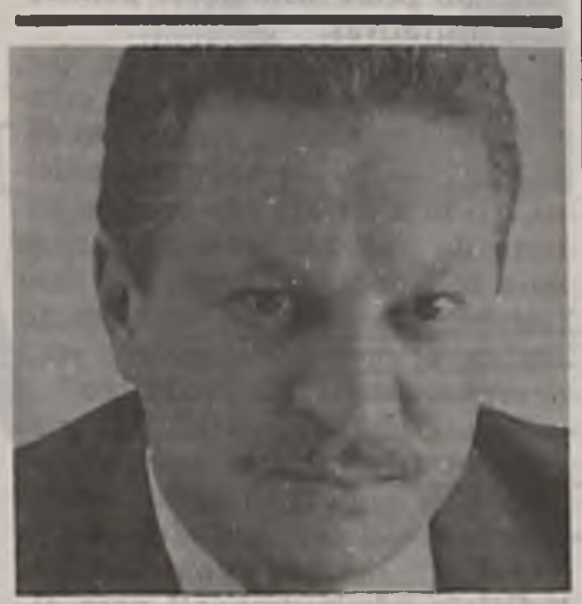

Estado e o papel da administração pública, Competências do Poder Legislativo e do Poder Executivo em matéria de descentralização; gestão, avaliaça e controle da administracão - proporcionaram oportunidade para análise dos instrumentos legais, ficando evidentes, em vários momentos, certos aspectos de coerência e efetividade que faltam aos meios atuais para conduzir aos objelivos que lhes deram origem.

Selecionar desse debate os pontos mais importantes que foram objeto de exame não é tarefa fácil. Constituem a base sobre a qual os técnicos, administradores, polítiços e legisladores trabalharão, com o intuito de criar o ambiente propicio ao pleno exercício dos direitos de cidadania.

Entretanto, o esforco deve começar imediatamente e apesar da dificuldade de isolar e tratar principios e diretrizes dependentes de aspectos institucionais, politicos, sociais e es-

- Doutor em pedagogia e gerente de Treinamento e Desenvolvimento de Recursos Humanos da Secretaria de Modernizaçáo e Reforma Administrativa do Ministério da Administraçáo 